\title{
Special Issue: Papers from the 3rd International Conference on Structural Adhesive Bonding (AB 2015), Porto, Portugal, 2-3 July 2015
}

\author{
Lucas F. M. da Silva ${ }^{1 *}$ and Robert D. Adams²
}

*Correspondence: lucas@fe.up.pt

1 Departamento de Engenharia Mecânica, Faculdade de Engenharia, Universidade do Porto, Rua Dr. Roberto Frias, 4200-465 Porto, Portugal Full list of author information is available at the end of the article

\section{Guest Editorial}

This special issue of Applied Adhesion Science (AAS) contains selected papers presented at the 3rd International Conference on Structural Adhesive Bonding (AB 2015). AB 2015 was chaired by the two of us and was held in Porto, Portugal during July 2-3, 2015. The goal of the conference was to provide a unique opportunity to exchange information, present the latest results as well as to discuss issues relevant to structural adhesive bonding research today. Approximately 160 papers were presented by researchers from more than 30 countries. In order to disseminate the work presented at AB 2015, selected papers were prepared which resulted in the present Special Issue.

The study of Schneider and Wrobel deals with use of high-energy laser radiation for surface preparation of magnesium for adhesive applications. High strength adhesive bonding of magnesium-alloys could be achieved. This fast physical process fulfils all legal requirements concerning environmental protection and occupational safety and also has low operating costs.

Kemiklioglu et al. investigated the failure strengths of adhesively bonded joints with brittle and ductile adhesives by repeated impact. Useful information was generated to help designers who need information on mechanical properties of ductile and brittle adhesives under single and repeated impacts. The study of Moller et al. aims to determine the behaviour of a two-component adhesive regularly used to join pieces in acid mist extraction systems in mining applications. The specimens were tested at 20,50 and $80^{\circ} \mathrm{C}$. From the results obtained, it is possible to appreciate that the adhesive at $50{ }^{\circ} \mathrm{C}$ decreased its strength by $14 \%$ with respect to those at the reference temperature of $20^{\circ} \mathrm{C}$.

Assih et al. describe an experimental and theoretical analysis of strengthened damaged concrete corbel by gluing carbon fibre fabrics. The study showed that the bonded composite fibre fabrics can be a convenient and effective strengthening method of concrete structures. A theoretical analysis is presented describing the behaviour of strengthened damaged concrete corbel using the damage theory of reinforced concrete beams.

Applications of adhesive bonding are described in 2 papers. Ayyildiz et al. evaluate the shear bond strength (SBS) of three different cements to zirconia and lithium

(C) 2015 da Silva and Adams. This article is distributed under the terms of the Creative Commons Attribution 4.0 International License (http://creativecommons.org/licenses/by/4.0/), which permits unrestricted use, distribution, and reproduction in any medium, provided you give appropriate credit to the original author(s) and the source, provide a link to the Creative Commons license, and indicate if changes were made. 
disilicate ceramic surface after thermal cycling. It was concluded that the self adhesive resin cement had the highest shear bond strength values when bonded to lithium disilicate and zirconia ceramic surface. However zinc-phosphate cement demonstrated significantly lower shear bond strength values for both ceramic groups. Wisner et al. used adhesive bonding for a fully autonomous pile driving monitoring of an impact-driven large-scale foundation structure for an offshore wind farm. A boosted moisture-curable polyurethane adhesive applied on appropriate primer coatings was successfully applied with all hardware of the measurement system.

The preparation of this Special Issue has been an interesting experience for the guest editors. The review process gave a deeper insight into the various aspects of joint design and the opportunity to discuss in detail the manuscripts directly with the authors. We would like to thank the authors for their patience with the process and the reviewers for providing critical evaluations of these manuscripts. Finally, we especially thank Dr. Silvio de Barros, Editor-in-Chief of AAS, who made this Special Issue possible.

\footnotetext{
Author details

1 Departamento de Engenharia Mecânica, Faculdade de Engenharia, Universidade do Porto, Rua Dr. Roberto Frias, 4200-465 Porto, Portugal. ${ }^{2}$ Department of Engineering Science, University of Oxford, Parks Road, Oxford, UK.
}

Received: 2 December 2015 Accepted: 2 December 2015

Published online: 12 December 2015

Submit your manuscript to a SpringerOpen ${ }^{\circ}$ journal and benefit from:

- Convenient online submission

- Rigorous peer review

- Immediate publication on acceptance

- Open access: articles freely available online

- High visibility within the field

- Retaining the copyright to your article

Submit your next manuscript at $\boldsymbol{s p r i n g e r o p e n . c o m ~}$ 